\title{
Failure of Postexposure Prophylaxis in a Patient Given Rabies Vaccine Intramuscularly in the Gluteus Muscle, Himachal Pradesh, India
}

\author{
Omesh Kumar Bharti, Vivek Sharma ${ }^{1}$ \\ State Intradermal Antirabies Clinic and Research Centre, DDU Hospital, Shimla, 'Department of Health and Family Welfare, Himachal Pradesh, India
}

\section{Abstract}

A 48-year-old male was bitten by a dog on the forehead and on the RIGHT side of left eyebrow on November 26, 2017, at 2 pm. The patient was immediately rushed to a nearby private hospital where an MBBS doctor gave him immediate wound wash with soap and water and prescribed five doses of rabies vaccine intramuscularly (IM). Since the patient weight was $60 \mathrm{~kg}$, he was also prescribed $2400 \mathrm{IU}$ of equine rabies immunoglobulin (ERIG), but as eRIG was not available, it was not administered. All the four doses of rabies vaccine were given IM in gluteus muscle. On December 17, 2017, the patient was brought to the Government Regional Hospital Hamirpur with the symptoms of difficulty in swallowing water (Hydrophobia) for 2 days. He was given injection diazepam and referred to Rajinder Prasad Government Medical College Tanda, Kangra, Himachal Pradesh, India, where he died of suspected rabies on December 19, 2017. The explicit consent to publish this report and picture was taken from the relatives of the patient, so that others have a lesson from this case report.

Keywords: Gluteus muscle, postexposure prophylaxis, rabies

\section{INTRODUCTION}

Rabies is most dreaded infectious disease and is invariably fatal once symptoms appear. The current estimates suggest that approximately 60,000 human deaths occur each year globally and the burden of disease being primarily borne in Asia and Africa, especially in rural areas. ${ }^{[1]}$ The estimated deaths have remained the same for the last decade despite a shift from costly option of intramuscular (IM) vaccination to intradermal rabies vaccination. Dogs are the principal reservoir responsible for $98 \%$ of human fatalities. The burden of human rabies can be substantially reduced through improved access to rabies postexposure prophylaxis (PEP), which, if administered promptly and properly, after an exposure, will prevent the fatal outcome of the disease.

\section{Case Report}

A 48-year-old male was bitten by a dog on the forehead on the right side of left eyebrow on November 26, 2017, at $2 \mathrm{pm}$ in Sankar village of Nadaun in Hamirpur, Himachal Pradesh, India. The patient was immediately rushed to a

\begin{tabular}{|l|l|}
\hline \multicolumn{3}{|c|}{ Access this article online } \\
\hline Quick Response Code: & Website: \\
\hline & www.ijccm.org \\
\cline { 2 - 2 } & \\
\hline
\end{tabular}

nearby private hospital where an MBBS doctor gave him immediate wound wash with soap and water and prescribed five doses of rabies vaccine intramuscularly (IM). Since the patient weight was $60 \mathrm{~kg}$, he was also prescribed $2400 \mathrm{IU}$ of equine rabies immunoglobulin (eRIG), but as eRIG was not available, it was not administered. All the four doses of rabies vaccine were given IM in gluteus muscle in the buttocks. On December 17, 2017, the patient was brought to the Government Regional Hospital Hamirpur with the symptoms of difficulty in swallowing water (Hydrophobia) for 2 days. The patient had symptoms of hydrophobia having a fixed gaze [Figure 1] with dilated pupil in-between fits of hydrophobia. He was given injection diazepam and referred to Rajinder Prasad Government Medical College Tanda, Kangra, Himachal Pradesh, India, where he died of suspected rabies

Address for correspondence: Dr. Omesh Kumar Bharti, State Intradermal Antirabies Clinic and Research Centre, DDU Hospital, Shimla, Himachal Pradesh, India. E-mail: bhartiomesh@yahoo.com

This is an open access article distributed under the terms of the Creative Commons Attribution-NonCommercial-ShareAlike 3.0 License, which allows others to remix, tweak, and build upon the work non-commercially, as long as the author is credited and the new creations are licensed under the identical terms.

For reprints contact: reprints@medknow.com

How to cite this article: Bharti OK, Sharma V. Failure of postexposure prophylaxis in a patient given rabies vaccine intramuscularly in the gluteus muscle, Himachal Pradesh, India. Indian J Crit Care Med 2018;22:189-90. 


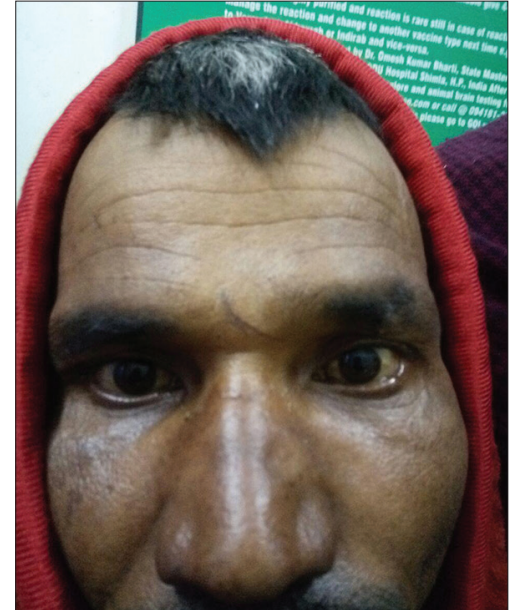

Figure 1: The patient with symptoms of hydrophobia having a fixed gaze with dilated pupil in-between fits of hydrophobia

on December 19, 2017. The explicit consent to publish this report and picture was taken from the relatives of the patient, so that others have a lesson from this case report.

\section{Discussion}

The recent WHO Weekly Epidemiological Record (WER) ${ }^{[2]}$ highlights the new evidence from Cambodia and United Republic of Tanzania that when through wound washing and prompt administration of rabies vaccine are provided to category III bite victims, $99 \%$ of them survive, that means even without administration of rabies immunioglobulins (RIG). A recent publication from Maharashtra, India, ${ }^{[3]}$ strengthens that the theory put forward by WER. All the four patients in Maharashtra who were bitten by a rabid dog were given only rabies vaccine in deltoid muscle and no RIG was given (personnel communication with the authors over phone), all of them survived, and one female patient who had abrasions in the right foot due to same dog's claws did not get vaccine thinking bites and not claws abrasions can cause rabies and instead opted for local herbal remedies and later died due to rabies. In our case, all the four shots of rabies vaccine were given in the gluteus muscle IM and no RIG was given though the patient was bitten on the face. The WHO guidelines ${ }^{[4]}$ clearly prohibit giving rabies vaccine IM in gluteus region. The patients in Maharashtra survived with rabies vaccine only given in deltoid muscle while our patient was given rabies vaccine in gluteus muscle and that proved to be ineffective and lead to development of hydrophobia and death due to rabies. This case report again highlights the peril of giving rabies vaccine IM in gluteus muscle that may lead to rabies and should be avoided. Similar failures have been reported in case of giving rabies immunoglobulin IM in gluteus muscle ${ }^{[5]}$ and medical fraternity needs to be alert not to give these rabies biologicals IM in gluteus muscle to avoid the danger of PEP failure, leading to the dreaded disease like rabies. In 2014, the authors examined a 24-year-old male bitten by a suspected rabid dog on right leg weighing $62 \mathrm{~kg}$ and who was given eRIG $8.5 \mathrm{ml} \mathrm{IM}$ in right buttocks 3 days ago; the rapid fluorescent focus inhibition test titers were barely detectable, proving the uselessness of giving rabies biologicals IM in buttocks.

\section{Declaration of patient consent}

The authors certify that they have obtained all appropriate patient consent forms. In the form the patient(s)/close relatives has/have given his/her/their consent for his/her/their images and other clinical information to be reported in the journal. The patients understand that their names and initials will not be published and due efforts will be made to conceal their identity, but anonymity cannot be guaranteed.

\section{Financial support and sponsorship}

Nil.

\section{Conflicts of interest}

There are no conflicts of interest.

\section{References}

1. Hampson K, Coudeville L, Lembo T, Sambo M, Kieffer A, Attlan M, et al. Estimating the global burden of endemic canine rabies. PLoS Negl Trop Dis 2015;9:e0003709.

2. WHO Weekly Epidemiological Record, No. 48; 2017;92:729-48. Available from: https://reliefweb.int/sites/reliefweb.int/files/resources/ WER9248.pdf. [Last accessed on 2018].

3. Bawaskar HS, Bawaskar PH, Bawaskar PH. Rabies: A novel clinical presentation. Indian J Crit Care Med 2017;21:872-4.

4. WHO Expert Consultation on Rabies, Second Report. Available from: http://apps.who.int/iris/bitstream/10665/85346/1/9789240690943_eng. pdf. [Last accessed on 2018].

5. Chomchay P, Khawplod P, Wilde H. Neutralizing antibodies to rabies following injection of rabies immune globulin into gluteal fat or deltoid muscle. J Travel Med 2000;7:187-8. 